\title{
A Processual Concept of Media Generation
}

The Media-Generational Positioning of Elderly People

\author{
Andreas Hepp, Matthias Berg \& Cindy Roitsch
}

\begin{abstract}
With a focus on elderly people this article puts forward a concept of media generation as a thickening of one or more age groups of people who in their media appropriation share a specific experience space of mediatization and subsequently, based on their personal media biographies, develop a shared self-image as a media generation. Such a conceptualisation grasps media generation as a process. It operates with the central aspects of media relatedness, media-generational specifics of appropriation, and self-positioning. This offers an understanding of elderly people after retirement as members of a mass-media media generation. As the qualitative empirical analysis presented in this article demonstrates, members of this mass-media media generation define themselves in contrast to younger media generations.
\end{abstract}

Keywords: media generation, media biographies, mediatization, generational self-positioning, elderly people

\section{Introduction}

Especially when holding qualitative interviews on media appropriation and communicative networking with elderly people, one repeatedly comes across comments like 'in my generation...' or 'in our generation...'. This is followed by statements concerning the media contents said to be preferred by certain age groups or one's attitude with regard to specific media. Analysing such interviews in a comparative perspective, it becomes apparent that although the individual references made within an age group may well be identical, the concretely appropriated media as well as practices of media use can be highly diversified. We are thus confronted with a situation in which, although the empirical evidence contributes towards an understanding of the concept 'media generation', we cannot conclude that any one particular age group adopts a uniform way of dealing with media. Against this backdrop, in this contribution we wish to put forward arguments for a process-oriented concept of media generation. In essence, we argue that a mass-media media generation of elderly people is defined by individuals' experiences of mediatization in the characteristic phases of their life course. Such shared experiences, however, 
do not presuppose uniform ways of appropriating the respective media. Nonetheless, they do constitute a major point of reference for media-generational self-positioning. In order to render this understanding more tangible, in the following first section we will elucidate the processual concept of media generation. We then move on to discuss the results of an empirical study on the media-generational positioning of elderly persons as members of a mass-media media generation. In conclusion, based on this we put forward suggestions for future research on media generation.

\section{Media generation as a processual concept}

A suitable point of departure to explain the concept of media generation is the generation concept developed by Karl Mannheim, which is often cited in empirical communication and media research (cf. Bolin 2016, Volkmer 2006, Vittadini et al. 2013). According to this view, it is necessary to distinguish concepts of generation from an age-group construct based on cohorts. As Mannheim points out, every generation is marked by a characteristic 'social location' (Mannheim 1952: 291) in an historical context. This 'social location' - at least in tendency - is in accordance with generation-specific 'experiences' and 'events' (Mannheim 1952: 297) that occur during certain phases of an individual's biography. In this respect, Mannheim assumes that a generation is influenced especially by the experiences and events occurring in the formative phase of an individual's younger years. However, one should not lose sight of the occurrences that happen in later years, especially when these are connected with determining generationspecific turning points in individuals' biographies (Mannheim 1952: 282).

Hence, approaching media generation in such a way means to focus on media-related experiences and events. In so doing, media is to be understood in a dual sense: namely, on the one hand in connection with experiences and events with certain media contents and, on the other hand, with regard to the experiences and involvements with certain media technologies (Schäffer 2003; also see Livingstone \& Helsper 2007, Silverstone et al. 1991, Hartmann 2006). As a first response, this means that the concept of media generation refers to a type of 'social location' that is constituted via characteristic mediarelated experiences and involvements. At the subjective level, therefore, belonging to a media generation must always result from an individual's personal media biography.

We can grasp the latter as part of an increasingly individualised biography (cf. Volkmer 2006). Thus, media biography denotes each individual's subjective but nonetheless generationally typical history of use and appropriation of media as technologies and contents (cf. among others Hickethier 1982, Rogge 1982, Mohn 1987, Sander \& Vollbrecht 1989, Charlton \& Neumann-Braun 1992, Prommer 1999, Aufenanger 2006, Jörissen $\&$ Marotzki 2009). When it comes to media biographies, therefore, we have to address the central question as to 'the significance and relevance of media for the individual construction and reconstruction of a biography, and how the pattern of media use and media appropriation develops and undergoes change' [authors' translation] (Vollbrecht 2009: 25). Subsequently, to research media generation we have to investigate empirically the typical elements of media biographies and their relation to one another.

However, we cannot assume that every age cohort is likely to be a 'generation as an actuality' (Mannheim 1952: 302-303) in the sense of consciously perceived, shared experiences and events. If we understand media generation in the sense outlined above, 
when their media-related experiences and events are identical, media generations can encompass several different age cohorts. Conversely, in phases of accelerated media change, it may also happen that different media generations follow on one another in quick succession. This begs the question as to whether and when it makes sense to talk of a media generation.

Taking this discussion to another level, it is possible to grasp media generation in a processual perspective. One can then define media generation as a thickening of one or more age groups of people who in their media appropriation share a specific experience space of mediatization and subsequently, based on their personal media biographies, develop a shared self-image as a media generation. Such a concept of media generation issues from its processual character in a dual sense: On the one hand, media-related experiences are made in relation to certain life phases on an ongoing basis in the life course. On the other hand, the media-generational self-image is generated in an ongoing 'doing' (cf. Wachelder 2016). Here, we feel it is important to emphasise the following three points of our definition, namely: the media-relatedness of media generation, the subsequently associated understanding of media-generational specifics, and generational positioning.

With regard to media relatedness, we want to point out that in our aforementioned definition we deliberately speak only of media generations. By so doing, we want to make clear that the conclusions we draw refer solely to the media experiences and resultant processes of communicative construction that are characteristic for one generation. Although we, too, subscribe to the view that media are essential to the 'fundamental learning and appropriation processes that lead to the formation of generation-specific conjunctive experience spaces' (Schäffer 2003: 89) in general, our concept of media generation does not refer to a generation and the entire experience space it shares, but rather solely to those experiences that are media-related. In the circumstance that we refer to a particular media generation, one should not conclude that the term actually corresponds to a particular generation in the general sense of the word - like 'post-war generation' or the 'sixty-eight generation'.

From an empirical standpoint, our concept of media generation entails grasping the media-generational specifics of experiences of mediatization. This is constituted in the way media are appropriated in a dual sense, i.e. in the appropriation of media contents as well as in the media technologies used. We are therefore confronted with a generational 'specific constellation' (Paus-Hasebrink et al. 2009: 18) of media appropriation in the respective socio-cultural context of different 'communicative figurations' (Hepp $\&$ Hasebrink 2014). These correspond to 'the common and specific normality experiences and interpretative frame surrounding media' (Fromme 2002: 157; also see PausHasebrink et al. 2009: 18). Thus, for such an understanding of generational specifics, it is important that the term 'media generation' is not merely taken to mean that all members of a media generation share identical practices of media appropriation. Rather, it is argued that a generation-specific experience space of mediatization encompasses different practices of media appropriation, depending on precisely where one is located in this experience space. However, if we consider the overall 'constellation' of a media generation, it does not vice versa follow that it is characterised merely by an arbitrary collection of different practices. Rather, in the case of a specific, media-related experience space of mediatization, it may well be expected that we are likewise confronted 
with a particular 'constellation' comprising different practices. This is reflected in individuals' biographies: Thus, a once-learned practice with a particular medium does not result in a 'constant pattern of use' with this medium throughout the whole course of an individual's media biography. Other media will follow, certain ways of dealing with a medium change over an individual's 'life course' (Beck et al. 2007, Bolin \& Skogerbø 2013, Claessens 2013, Westlund \& Weibull 2013; from a sociological perspective: Green 2010, Heinz et al. 2009) and its typical transitions (school, career, parenthood, retirement etc.). Hence, for the biography course of a media generation we are able - and this is the assumption to be tested empirically - to identify typical patterns of change in the overall constellation of media-related practices which, in turn, point to typical patterns of the generation-specific media biography. However, this is not to mean that every pattern of media use can be interpreted as an expression of a particular media generation. To the contrary: the specific patterns shared by a media generation can only provide but a section of the overall pattern of how media are appropriated.

When we speak of media-generational positioning, we mean that members of a particular media generation position themselves within the horizon of their individual media-related experiences. This once again underlines the hypothesis that the term media generation entails more than an age cohort (Pietraß \& Schäffer 2011). Accordingly, the term also entails a certain collectively shared perspective on one's individual position in a media generation (Opermann 2013, Vittadini et al. 2013). With this we mean a self-positioning; for example, as members of a generation that grew up without electronic media being available during their formative years and for whom television is still something special; as members of a media generation that grew up with the television, radio and record player and later entered into the computer era; or as members of a generation that have grown up in an age when the computer and digital media are simply matters of course. The foregoing illustrates once again why it makes sense to grasp media generations as phenomena of thickenings. Thus, even today there are young people who grow up more exposed to television, radio, and music media than to digital media and, therefore, do not naturally belong to the 'digital generation' (Buckingham \& Willet 2008).

On the basis of such a concept of media generation, we can assume that 'waves of mediatization' (Couldry \& Hepp 2017: 39, Hepp 2013: 58, Krotz 2007: 48) signify relevant watersheds. By 'waves of mediatization', we mean more than simply the arrival of a 'new' medium in the process of mediatization. Rather, reaching beyond this, we understand the term to mean the emergence of a new media environment. The most recent wave of mediatization we can identify is digitalisation. Digitalisation entails much more than merely the emergence of a 'new' medium like, for example, the mobile phone - it also impacts on a number of 'old' media such as television, cinema, radio etc. By the same token, digitalisation does not affect a specific media generation - it impacts the experience space of different media generations, albeit in different phases of their media biography and life course.

Hence, our processual concept of media generation entails understanding media generations not as static phenomena, but rather in each case as a partial aspect of the biography and life course from the perspective of specific media-biographical dynamics. For our research hypothesis with regard to the wave of mediatization triggered by digitalisation - which has brought about a fundamental change to the experience space 
of mediatization - we distinguish three different media generations. First, the massmedia media generation that experienced the radio, cinema, print, post, and landline telephone in their formative phase; later on got to know television, and in old age is confronted with digitalisation as a wave of mediatization. (This is the generation that we will focus on in this article.) On the other hand, and at the other extreme, there is the 'digital media generation' (Buckingham \& Willet 2008) that grew up after the emergence of digital media and for whom the change brought about by digitalisation is a matterof-course component of their overall media environment (Hepp et al. 2014: 22-31). Finally, between these two - a quasi 'sandwich generation' - the secondary digital media generation that also grew up with the television, cinema, radio, print, post and landline telephone, but then more or less comprehensively embraced digital media in the course of their (vocational) life, making it an integral part of their individual media repertoire.

As we said in the beginning, with reference to this thematic issue our focus is not the comparison of the different media generations, nor a comprehensive analysis of the media appropriation and communicative networking of the mass-media media generation. This would be far beyond the scope of a journal article. Rather, we want to explain why a processual understanding of media generation presents a helpful starting point for understanding the ongoing everyday sense-making within what we can call massmedia media generation.

\section{Methods}

On the basis of the processual concept of media generation illustrated in the foregoing, in a project undertaken in the frame of Priority Programme 1505 'Mediatized Worlds', funded by the German Research Foundation, we researched the communicative networking and community building of young people (16-30 years old), middle-aged persons (31-59 years old) and elderly people (older than 60 and retired). Our research was based on methods of contextualised communication network analysis (cf. Hepp et al. 2016). In the frame of a qualitative, media-ethnographic approach (Bachmann \& Wittel 2006), the aim of the project was to investigate individuals' communicative relations, the related practices and meanings ascribed to them, as well as processes of communicative construction. The core method applied bases on three qualitative instruments of data collection. To capture dimensions of meaning, we carried out qualitative interviews lasting on average 125 minutes. During the interviews, we inquired into interviewees' media appropriation and their relevant every-day 'communitisations' (Vergemeinschaften, that is the processes of building up belongings to various kinds of communities), as well as the practices related to the two. In the course of the interviews, the interviewees were requested to draw their subjective view of their communicative networks on two unstructured cards and to comment on them. In this way, we aimed to capture the structural dimension of their communicative networking. In order to describe the process dimension of their egocentric communication networks and communitisation, we employed semi-standardised media diaries in the form of printed notebooks or a mobile telephone app. ${ }^{1}$

The interview partners were selected according to the 'theoretical sampling' approach (Glaser \& Strauss 1999: 45-78). For practical reasons, due to the complexity of our methodology this research was undertaken between 2010 and 2017: In a first wave between 
November 2010 and September 2011, we interviewed 60 adolescents and young adults aged between 16 and 30. Since a media-generational perspective did not develop until the research process had started, we extended our sample by two additional waves of data collection. Thus, a second wave was carried out between May 2013 and July 2014 and encompassed 58 older retired persons aged between 60 and 88 years. In the third wave between April 2014 and January 2017 we interviewed 41 middle-aged persons (between the ages of 31 and 59). All three phases of data collection were carried out in the German towns of Bremen and Leipzig and their surrounding areas.

The data were evaluated according to a coding procedure oriented to 'grounded theory' (Glaser \& Strauss 1999, Morse et al. 2009). In the coding process, we were interested in patterns of communitisation as well as the structures, processes and meanings of communicative networking and corresponding practices of media appropriation. We then subjected the derived patterns to a media-generational comparison. This took place in two steps: in a first step, we examined to what extent the three age groups we investigated can be understood as media generations in respect of their experience of mediatization and their generational self-image. This is what we will concentrate on in the following section of this article, using the example of elderly people's mediagenerational positioning. In a second step, we then described the respective media generations' specific patterns of communicative networking and communitisation (for further details, see Hepp et al. 2017).

\section{Self-positioning as members of a mass-media media generation}

To grasp the character of what we call mass-media media generation, an appropriate starting point is the media-generational self-positioning of the elderly people interviewed by us. This is articulated above all in the 'meaning dimension' of communicative networking. In their media-related generational self-positioning, the members of the mass-media media generation we interviewed are characterised by three central aspects: first, we perceived a general tendency to adopt a certain distance to digital technology. However, this is not expressed in an across-the-board rejection of the media concerned, but rather in a spectrum ranging from complete disregard, through mild interest, up to regular everyday use. Second, this self-positioning manifests itself in the way older persons draw a distinction between their generation and other (mostly younger) generations. This distinction is illustrated both by means of ascribing competences related to media technology to (mostly) younger people as well as by contrasting the attitudes, practices and competences of younger persons with those of their own generation. In so doing, the perspective of generation mainly follows the classical model of family generations: their own generation is contrasted with the generations of their children, grandchildren, and in some cases also the parents' generation. As an alternative to technological aspects, media-generational distinctions and contrasts can also refer to the contents of media. Third, aspects of distance from technology and contrasting with other generations are then sporadically supplemented by a positioning of the self in the context of characterising their own media generation. We thus witness an inherent media-generational differentiation as a self-reflection on the heterogeneity of media generation. The main point here is that such a position is not 'given' but ongoingly articulated as part of elderly persons' everyday doings and reflections on their media practices. 


\section{Media-generational distance from technology}

When it comes to the attitude adopted by members of the mass-media media generation with regard to digital media technology, the spectrum captured in our data ranges from rejection and indifference, through uncertainty, up to interest, curiosity, and downright enthusiasm. However, even in the latter case, we can generally observe a certain distance to digital media that is manifested in the media-generational positioning (as well as in specific patterns of media use concerning communitisation; see Hepp et al. 2017). Among other things, this is due to the fact that the majority of our interview partners either never at all or comparatively late in life (usually in the course of late professional life) came into contact with technologies like the computer or the Internet. And even in the very few cases in which electronic data processing did play a role in their earlier occupational biographies, which indicates a rather open-minded approach to digital media, at some time or other they begin to adopt a distanced attitude towards newly arising media developments. For instance, Helga Baier ${ }^{2}$ (74 years old, Leipzig), who in the 1970s completed a data processing course for women and today feels 'married to her computer', but nonetheless states: 'Twitter, Facebook that's nothing for me, out of the question, all a bit weird, isn't it?'. And another example, Herbert Baumgarten (68 years old, Bremen), who as a former software developer himself helped shape 'the beginnings of the PC world' and today offers computer courses for senior citizens: On the one hand, he says he can no longer keep up with the fast pace of technological development - and 'not sure I really want to'. On the other hand, he finds it irritating that some of the younger people he knows post 'the most private stuff' like details of pregnancies or sports injuries on Facebook.

More often than such 'pioneers', we find people in our sample who, although they are open-minded about new media technology, discern a certain lack of 'normality' in dealing with them. For example, Nils Knebel (72 years old, Bremen suburb):

I think my generation has some trouble with it [...] Umm, I see it from my work and from the colleagues who had real difficulty, and either didn't yet know enough about it or even didn't want to [...]

On the other hand, he always did his best to master the emerging new computer technology so that after retirement he would 'at least know enough to get by'. Walter Müngersdorf (79 years old, Bremen) is likewise practiced in the use of digital media. Notwithstanding, he still finds it more difficult to use his new tablet PC than the former models, which might perhaps also have something to do with the fact that 'I'm so old', as he puts it. Konrad Schreiber (77 years old, Bremen) thinks the distance is because he was 'always sceptical from the beginning' in respect of new technologies, which he puts down to a certain 'senile stubbornness'. He then adds: 'It was clear the development would continue, but at such a pace and so networked... I'd never have thought it.'

These examples show that even those people who did not shut themselves off from new media technologies at the beginning tend to adopt more distanced attitudes in later life. In the case of Konrad Schreiber, for example, these are the social network sites, above all Facebook, on which 'we perhaps reveal too much about ourselves', as he says; or, as Henrik-Hugo Wehnhold (63 years old, Bremen) puts it, 'we no longer have our personal data under control'. 
Yet, the distance to more modern technologies may also be due either to lack of practice with some kinds of media - like Elvira Mangold (64 years old, Leipzig) who says, 'Well, I actually don't need a computer and only seldom write emails' - or plain rejection, like Wilfried Detlef (75 years old, Bremen):

I couldn't give a stuff, I just can't be bothered with the shit, so, that's what I think about it, when I grew up with it, when I see it with my grandchildren, how they get along with it, and 'grandpa, you must do it like this' and zack, zack, zack and I think it's great, you know, but why should I bother with it now! What for? I'm 75 , so what the hell?

Besides his own personal clear-cut distance to digital media, here Wilfried Detlef is addressing a central mechanism of the media-generational self-positioning of older people, i.e. that of drawing a distinction between their own media generation and younger people.

\section{Media-generational distinction}

A significant aspect of the media-generational self-positioning of the mass-media media generation is the distinction they draw between their own and other media generations. In such an analysis, we can see how our distinction between a digital media generation, a secondary digital media generation and a mass-media media generation is a point of reference in everyday practice, and to what extent the formative phase of the respective media biography is of importance.

A first example is Claudia Behrend (71 years old, Bremen), who for her media generation maintains that 'when it comes to communication' the 'familiar' media dominate, meaning media - like the 'telephone, television, newspapers' - that are anchored in her generation's biographies. The computer, on the other hand, remains rather ' $[\mathrm{a}]$ foreign word for many people'. This is ongoingly contrasted with the younger media generations of children (secondary digital media generation) and grandchildren (digital media generation). This dichotomisation of old and young construed by the interviewees bases, firstly, on the competences ascribed to the young in respect of using digital media technologies and, secondly, on contrasting this generation with theirs.

The competences ascribed to the digital media generation are mainly that they grew up with the computer, Internet and mobile telephone; and, being surrounded by such technologies, members of the generation are therefore able to use them as a matter of course in a quite 'natural' fashion. Thus, in the eyes of Elvira Mangold, 'young people' have 'a completely different take on everything' as they 'are surrounded by more technology'. Konrad Schreiber says that young people 'know nothing different, they grow up with it', and virtually in the same words, Wilfried Detlef addressed his interviewer as follows: 'you're age group, you live with it; grow up with it, with the computer'. Referring to advices given to her by her grandson while purchasing a smart phone, Hedwig Knebel (69 years old, Bremen suburb) states: 'The young people, they grow up with it, I think there are hardly any who don't know how to use it.'

Her spouse, Nils Knebel, traces the competences shown by young people in respect of using digital media to the education system: 'Our children, I suppose they were; it all began in school, but especially during job training, they were already, I won't say 
dependent, but with both feet in EDP.' In consequence, according to Kurt Gerau (76 years old, Bremen), 'when they now sit down at the PC or whatever [...] young people work quite differently' to the way he was used to.

Selectively, therefore, the competences ascribed to young people as members of a digital media generation and their use of media are also characterised by a critical undertone that can be traced back to perceived resulting consequences. Thus, in the view of Paul Witzig (66 years old, Bremen), as result of technologies like GPS navigation and the computer, young people are losing the ability to read maps and road maps or handwriting: 'With such loss of competencies it's already got to the stage that most of them are already completely unable to write by hand'. The most problematic thing about 'today's generation' for Claudia Behrend is above all, 'that they no longer have face-toface conversations, but rather nowadays do it on the Internet, talking together by phone'.

The position of the majority of people belonging to the mass-media media generation of the elderly is that when compared with younger people they perceive deficits in their own use of more modern media technologies. In contrast to the digital and secondary digital generations' perceived matter-of-course technology competence, they are often themselves only able to keep up with technological developments (assuming they are at all interested in doing so) with considerable effort: 'If a problem crops up', says for example Henrik-Hugo Wehnhold, and 'something doesn't function as I think it should, then I'm helpless'. He then seeks help from his flat mate, whom he describes as being 'professionally experienced in the use of computers':

She does it so fast that it's impossible for me to watch what she's doing and to learn, $[\ldots]$ that's a generational difference because [flat mate] is of course twenty years younger than me, so she is in her mid-forties, I'm almost mid-sixty, [...] I can see the difference.

The perception of such differences, which Henrik-Hugo Wehnhold here frames in a direct media generation comparison, might be due equally to recognition or to self-doubt. Elvira Mangold, for instance, relates how her four-year-old grandson once wanted to play a game on her computer and she was unable to help him. When he visited her again some four weeks later, this time he was perfectly able to start up and to play the computer game himself, whereupon she said: 'I could only stand next to him looking like some kind of idiot while he sits there and bangs it out, I was impressed, I can tell you.'

A similar statement referring to the contrast between young and old came from Erna Früh (77 years old, Bremen), who uses an iPad, computer and Internet simply because 'I want to keep my hand in a bit, you know, you want to follow what's happening in the world'. Old people wanting to 'keep their hand in' stand in contrast to young people with 'both feet in'. In a similar vein, Kurt Gerau (76 years old, Bremen) says he still 'wants to understand the new things coming along' - although, as opposed to the media generation his children belong to, he doesn't really need to have full command of them.

The difficulty members of the media generation brought up with mass-media face trying to find their way around in digital technologies is illustrated in the case of Kirsten Heise (69 years old, Bremen), who came into contact with computers and the Internet towards the end of her occupational biography:

I'm rather proud I was able to manage, having to cope with such a challenge at over sixty, while I could see my daughter, for her it all falls into place naturally, 
she is simply able to do it, that's how it is, as well as her friends and so on, there's a difference, I think.

Contrasting the media competences ascribed to younger media generations with one's own limited abilities appears to constitute an important motivation for members of the mass-media media generation to develop skills with digital communication technologies. Marianne Detlef (68 years old, Bremen), for instance, relates how she 'quietly acquired [her] own Skype program' so she could keep in touch via video telephone with her granddaughter who spent a semester studying abroad. 'And then I could join in again', she comments, something which she felt to be 'really important' within the family circle. Similarly, Ricarda Hilling (65 years old, Bremen) describes her approach to using the smart phone: 'When I see how small kids pick the thing up and already know where to put their finger, I'd have to be proper stupid if I couldn't do it myself'.

Yet, in the case of the elderly persons we interviewed, the distinction drawn between their own mass-media media generation and other media generations was not restricted to ascribing superior media competences to younger media generations and contrasting these with their own limited abilities. They also differentiate between the media contents - referring in particular to different tastes in music. For example, Konrad Schreiber prefers to listen to the radio station Radio Niedersachsen, which plays, 'what old people want to hear', namely, folk music and sentimental pop ballads. This shouldn't be taken to mean that it is not so much concrete musical genres or musical styles per se that characterise the individual media generations. Elvira Mangold, for instance, prefers 'works by Bach, Händel, and so on', but 'also the Beatles [...], that was our generation, you know, rock 'n roll and such things', and Kurt Gerau talks of the time 'after the War' and the 'American music' that then found its way to Germany. Thus, although the music preferences of members of the mass-media media generation may differ to some extent, the interviewees stress they have nothing in common with today's pop music - namely, the music their children (secondary digital media generation) and grandchildren (digital media generation) listen to: 'No way, oh no, and what they want to hear, you know, I just can't stand it', says Konrad Schreiber, for example. Several interviewees perceive this phenomenon of different preferences in music to be a 'generational given'. In various places, we thus find statements like those voiced by Elvira Mangold, who notes: 'Way back, when the Beatles got popular, it was just the same with my mother and our music: she thought it was awful, and that's how it is again nowadays.'

Based on the data we collected, music turns out to be the most dominant, but not the sole, media content elderly people refer to when attempting to characterise their massmedia media generation. Certain contents of television - like advertising or scenes of violence, for instance - come in for strong criticism. Elvira Mangold, for example, criticises her daughter's habit of watching US-American TV series, something she cannot understand: 'The Simpsons, that's just awful, fancy wanting to watch something like that.'

\section{Inherent media-generational differentiation}

A certain distance from technology can be seen as a basic tendency in the way people develop views of their own media generation. This is manifested in the way members of the mass-media media generation construct a dichotomisation of young and old 
based on ascription and contrast with regard to the significance of media technologies. Nonetheless, many of our interviewees realise that this type of media-generational selfpositioning should not be taken as unequivocally valid across all their contemporaries (including themselves). Rather, it is necessary to be aware of an inherent differentiation among members of the media generation brought up with mass media.

In this regard Claudia Behrend observes it 'is becoming more and more important for the younger members of our generation' to come to grips with media technologies like the computer. The most important inherent differentiation we observed, however, is that elderly people place themselves in relation to 'the other old people'. Kurt Gerau, for instance, criticises the fact that so many 'people of my age [...] don't want to know any more about PCs', adding the following analogy: 'I say, you know what? It's just as important today as a driving licence was fifty years ago', and immediately afterwards goes to the point out: 'For example, I do online banking, too.' This illustrates two things: first, media generations cannot be regarded as groups sharing and characterised by a homogenous attitude towards the appropriation of certain technologies and media contents; second, that this finding is reflected by the interview partners themselves.

Several aspects of this inherent differentiation are found in a part of the interview with Wiglaf König (74 years old, Bremen), in which he exemplarily mentions the group of five or six persons he regularly meets with in the pub. Besides himself and one or maybe two other persons who frequently use a PC, he says: 'Three of them are [not] in the least bit interested, zero interest, the other one [...] himself says no, he is eighty [...] the same for the other one, he just, they just bought themselves a smart phone'. This illustrates the large degree in which elderly people as part of a mass-media media generation differ in their approach to digital technology: the spectrum ranges from being open minded towards computers, through acceptance of some less-complicated devices, up to utter rejection (of certain) digital technologies. The latter is seen by Konrad Schreiber as typical for his media generation: 'Everyone says, what do I need a computer for, what do I need an iPad for, used to say it myself'. He, though, did eventually take the step, bought himself an iPad, and now says: 'Once you've got the thing, then you really get into it and find yourself using it more and more.'

In the case of Hilde Dörr (63 years old, Bremen), media-generational belonging is expressed among other things by the observation that younger people speak 'in their computer language', which, she says, is 'difficult for us older people' to understand. As a further feature of her media generation, she points out that many people can't cope with current media-technological developments. She illustrates what she means with the example of an acquaintance of hers who 'gave up his job when computers were introduced and he said, can't do it, don't want to, won't do it', something she 'never understood'. This is where Hilde Dörr distinguishes herself from her media generation, stressing 'I want to keep up with the times, that's important to me'.

In the case of Marianne Detlef, this kind of fundamental openness towards the computer, smart phone and Internet results likewise in her adopting a certain ambivalence towards her degree of belonging to her media generation. On the one hand, she states: 'I am old.' On the other hand, though: 'I try to behave like I don't really belong to the old ones, [...] through my contact with my grandchildren I am, you know, I keep up to date, so, I'm interested in what's going on.' Finally, Walter Müngersdorf even relates how, together with his grandson, he was able to help his working daughter learn how to 
use the Powerpoint presentation software, which in comparison with others of his age surely constitutes 'an exception'.

\section{Conclusion}

The subject of the empirical analysis reported in this contribution is the media-generational self-positioning of elderly people as one aspect of their mass-media media generation. This analysis alone clearly reveals two things: on the one hand, to what extent certain experiences of mediatization shared at a certain time in an individual's media biography shape their media generational self-image. On the other hand, the interview analysis described in the foregoing illustrates what ongoing 'doing media generation' means: What constitutes an individual's concept of media generation is established in an ongoing discourse of contrast with other media generations. Although the accordant statements made during the interviews were evoked by us, we can safely assume that similar processes of drawing media-generational distinctions are commonplace in everyday life. Therefore, it follows that when grasped as a process rather than a static phenomenon of homogenous use, media generation can be construed as an important structuring phenomenon in everyday (media) life.

In this vein, we would like to have this contribution and its empirical findings understood as a plea to adopt an appropriate research approach to media generation - when it comes to elderly people, but also in general. In order to fully grasp the structuring force of media generation, it has to be described in its processual genesis as well as in its process-related re-articulation. We therefore believe a concept of media generation that focuses on typical experiences of mediatization in the life course to be a highly suitable empirical point of departure.

\section{Notes}

1. More on the app and evaluation software we developed, under http://www.zemki.uni-bremen.de/en/ research/forschungs-app-medtag.html [01/12/2017].

2. The names of interviewees have been changed.

\section{References}

Aufenanger, Stefan (2006). Medienbiographische Forschung [Media Biographical Research], pp. 515-525 in Krüger, Heinz-Hermann \& Marotzki, Winfried (eds.) Handbuch Erziehungswissenschaftliche Biographieforschung. Wiesbaden: VS.

Bachmann, Götz \& Wittel, Andreas (2006). Medienethnografie [Media Ethnography], pp. 183-219 in Ayaß, Ruth \& Bergmann, Jörg (eds.) Qualitative Methoden der Medienforschung. Reinbek: Rowohlt.

Beck, Klaus; Rosenstock, Roland \& Schubert, Christiane (2007). Medien im Lebenslauf [Media in the Life Course], pp. 7-16 in Beck, Klaus; Rosenstock, Roland \& Schubert, Christiane (eds.) Medien im Lebenslauf. München: Kopaed.

Bolin, Göran (2016). Media Generations. London: Routledge.

Bolin, Göran \& Skogerbø, Eli (2013). Age, Generation and the Media. Northern Lights: Film \& Media Studies Yearbook, 11(1): 3-14.

Buckingham, David \& Willet, Rebekah (eds.) (2008). Digital Generations. New Jersey: Lawrence Erlbaum.

\section{Acknowledgements}

This work was supported by the German Research Foundation (DFG) within the Priority Program 1505 'Mediatized Worlds'. 
Charlton, Michael \& Neumann-Braun, Klaus (1992). Medienkindheit-Medienjugend [Media ChildhoodMedia Youth]. München: Quintessenz.

Claessens, Nathalie (2013). Nursing Home Residents Media Use rom a Life Course Perspective. Northern Lights: Film \& Media Studies Yearbook, 11(1): 35-50.

Couldry, Nick \& Hepp, Andreas (2017). The Mediated Construction of Reality. Cambridge: Polity.

Fromme, Johannes (2002). Mediensozialisation und Medienpädagogik [Media Socialisation and Media Pedagogics], pp.155-168 in Paus-Haase, Ingrid; Lampert, Claudia \& Süss, Daniel (eds.) Medienpädagogik in der Kommunikationswissenschaft. Wiesbaden: Westdeutscher.

Glaser, Barney G. \& Strauss, Anselm L. (1999). Discovery of Grounded Theory. New Brunswick: Aldine Transaction.

Green, Lorraine (2010). Understanding the Life Course. Cambridge: Policy Press.

Hartmann, Maren (2006). The Triple Articulation of ICTs, pp. 80-102 in Berker, Thomas; Hartmann, Maren; Punie, Yves \& Ward, Katie (eds.) Domestication of Media and Technology. London: Open University Press.

Heinz, Walter R.; Huinink, Johannes; Swader, Christopher S. \& Weymann, Ansgar (2009). General Introduction, pp. 15-30 in Heinz, Walter R.; Huinink, Johannes \& Weymann, Ansgar (eds.) The Life Course Reader. Frankfurt a. M.: Campus.

Hepp, Andreas (2013). Cultures of Mediatization. Cambridge: Polity Press.

Hepp, Andreas; Berg, Matthias \& Roitsch, Cindy (2014). Mediatized Worlds of Communitization, pp. 174203 in Hepp, Andreas \& Krotz, Friedrich (eds.) Mediatized Worlds: Culture and Society in a Media Age. London: Palgrave.

Hepp, Andreas; Berg, Matthias \& Roitsch, Cindy (2017). Mediengeneration als Prozess [Media Generations as Process], pp. 81-111, In: Krotz, Friedrich; Despotovic, Cathrin \& Kruse, Merle-Marie (eds.) Mediatisierung als Metaprozess. Wiesbaden: Springer VS.

Hepp, Andreas \& Hasebrink, Uwe (2014). Human Interaction and Communicative Figurations, pp. 249-272 in Lundby, Knut (ed.) Mediatisation of Communication. Berlin, New York: de Gruyter.

Hepp, Andreas; Roitsch, Cindy \& Berg, Matthias (2016). Investigating Communication Networks Contextually: Qualitative Network Analysis as Cross-Media Research. MedieKultur, 32(60): 87-106.

Hickethier, Knut (1982). Medienbiografien - Bausteine einer Rezeptionsgeschichte [Media Biographies Building Blocks of a History of Reception]. Medien und Erziehung 26: 106-215.

Jörissen, Benjamin \& Marotzki, Winfried (2009). Medienbildung - Eine Einführung [Media Education - An Introduction]. Bad Heilbrunn: Verlag Julius Klinkhardt.

Krotz, Friedrich (2007). Mediatisierung: Fallstudien zum Wandel von Kommunikation [Mediatisation. Case Studies on the Transformation of Communication]. Wiesbaden: VS.

Livingstone, Sonia M. \& Helsper, Ellen (2007). Gradations in Digital Inclusion: Children, Young People and the Digital Divide. New Media \& Society, 9(4): 671-696. doi:10.1177/1461444807080335.

Mannheim, Karl (1952). The Problem of Generations, pp. 276-320 in Kecskemeti, Paul (ed.) Essays on the Sociology of Knowledge. London: Routledge and Kegan Paul.

Mohn, Erich (1987). Fragen an die Medienbiographie- und Medienalltagsforschung [Questions to the Research of Media Biography and Media Everyday Life]. Medien und Erziehung 31: 261-267.

Morse, Janice M.; Stern, Phyllis N.; Corbin, Juliet; Bowers, Barbara; Charmaz, Kathy \& Clarke, Adele E. (eds.) (2009). Developing Grounded Theory: The Second Generation. Walnut Creek, CA: Left Coast Press.

Opermann, Signe (2013). Understanding Changing News Media Use: Generations and their Media Vocabulary. Northern Lights: Film \& Media Studies Yearbook, 11(1): 123-146.

Paus-Hasebrink, Ingrid; Schmidt, Jan-Hinrik \& Hasebrink, Uwe (2009). Zur Erforschung der Rolle des Social Web im Alltag von Heranwachsenden [On Researching the Role of the Social Web in the Everyday Life of Adolescents], pp. 13-40 in Schmidt, Jan-Hinrik; Hasebrink, Uwe \& Paus-Hasebrink, Ingrid (eds.) Heranwachsen mit dem Social Web. Berlin: Vistas.

Pietraß, Manuela \& Schäffer, Burkhard (2011). Mediengenerationen - vom Kohortenvergleich zu Generationsspezifischen Habitus [Media Generations - From Comparing Cohorts to Generational Habitus], pp. 323-332 in Eckert, Thomas; von Hippel, Aiga; Pietraß, Manuela \& Schmidt-Hertha, Bernhard (eds.) Bildung der Generationen. Wiesbaden: VS Verlag für Sozialwissenschaften.

Prommer, Elizabeth (1999). Kinobesuch im Lebenslauf [Going to the Movies in the Life Course]. Konstanz: UVK.

Rogge, Jan-Uwe (1982). Die biographische Methode in der Medienforschung [The Biographical Method in Media Research]. Medien und Erziehung 26: 273-287.

Sander, Uwe \& Vollbrecht, Ralf (1989). Biographische Medienforschung [Biographical Media Research]. BIOS, Zeitschrift für Biographieforschung und Oral History, 1: 15-30.

Schäffer, Burkhard (2003). Generationen - Medien - Bildung. Medienpraxiskulturen im Generationenvergleich [Generations - Media - Education. Comparing Generational Cultures of Media Practices]. Opladen: Westdeutscher Verlag. 
Silverstone, Roger; Hirsch, Eric \& Morley, David (1991). Listening to a Long Conversation. An Ethnographic Approach to the Study of Information and Communication Technologies. Cultural Studies, 5(2): 204-227.

Vittadini, Nicoletta; Siibak, Andra; Carpentier Reifová, Irena \& Bilandzic, Helena (2013). Generations and Media, pp. 65-81 in Carpentier, Nico; Schrøder, Kim \& Hallet, Lawrie (eds.) Transforming Audiences. London: Routledge.

Volkmer, Ingrid (2006). Globalization, Generational Entelechies, and the Global Public Space, pp. 251-268 in Volkmer, Ingrid (ed.) News in Public Memory. New York: Peter Lang.

Vollbrecht, Ralf (2009). Der Medienbiografische Ansatz in der Altersmedienforschung [The Media Biographical Approach in Researching Media and Old Age], pp. 21-30 in Schorb, Bernd; Hartung, Anja \& Reißmann, Wolfgang (eds.) Medien und Höheres Lebensalter. Wiesbaden: VS.

Wachelder, Joseph (2016). Regeneration: Generations Remediated. Time \& Society:, 1-21, online first, doi:10.1177/0961463X16678253.

Westlund, Oscar \& Weibull, Lennart (2013). Generation, Life Course and News Media Use in Sweden 1986-2011. Northern Lights: Film \& Media Studies Yearbook, 11(1): 147-172. 